\title{
Patterns of mortality after prolonged follow-up of a randomised controlled trial using granulocyte colony-stimulating factor to maintain chemotherapy dose intensity in non-Hodgkin's
} lymphoma

\author{
AR Clamp*,', WDJ Ryder', S Bhattacharya', R Pettengell' and JA Radford' \\ 'Department of Medical Oncology, Cancer Research UK, University of Manchester, Christie Hospital, Wilmslow Rd., Manchester M20 4BX, UK; \\ ${ }^{2}$ Department of Haematology, St George's Hospital Medical School, Cranmer Terrace, London SWI 7 ORE, UK
}

The effect of utilising granulocyte colony-stimulating factor (G-CSF) to maintain chemotherapy dose intensity in non-Hodgkin's lymphoma $(\mathrm{NHL})$ on long-term mortality patterns has not been formally evaluated. We analysed prolonged follow-up data from the first randomised controlled trial investigating this approach. Data on 10-year overall survival (OS), progression-free survival (PFS), freedom from progression (FFP) and incidence of second malignancies were collected for 80 patients with aggressive subtypes of $\mathrm{NHL}$, who had been randomised to receive either VAPEC-B chemotherapy or VAPEC-B + G-CSF. Median follow-up was I5.7 years for surviving patients. No significant differences were found in PFS or OS. However, I0-year FFP was better in the G-CSF arm (68 vs $47 \%, P=0.037$ ). Eleven deaths from causes unrelated to $\mathrm{NHL}$ or its treatment occurred in the G-CSF arm compared to five in controls. More deaths occurred from second malignancies (4 vs 2) and cardiovascular causes (5 vs 0 ) in the G-CSF arm. Although this pharmacovigilance study has insufficient statistical power to draw conclusions and is limited by the lack of data on smoking history and other cardiovascular risk factors, these unique long-term outcome data generate hypotheses that warrant further investigation. British Journal of Cancer (2008) 99, 253-258. doi: I 0.1038/sj.bjc.6604468 www.bjcancer.com

Published online I July 2008

(c) 2008 Cancer Research UK

Keywords: non-Hodgkin's lymphoma; granulocyte colony-stimulating factor; mortality pattern; dose intensity; pharmacovigilance; second malignancy

One of the major dose-limiting toxicities of cytotoxic chemotherapy for non-Hodgkin's lymphoma (NHL) is myelosuppression and subsequent susceptibility to infection. Haemopoietic colonystimulating factors (G-CSF and GM-CSF) are now commonly administered as an adjunct to cytotoxic chemotherapy in patients with NHL, to reduce the incidence of these toxicities based on data accrued from several randomised controlled studies (Pettengell et al, 1992; Bastion et al, 1993; Gerhartz et al, 1993; Aviles et al, 1994; Engelhard et al, 1994; Gisselbrecht et al, 1997; Zinzani et al, 1997; Doorduijn et al, 2003; Osby et al, 2003). It has also been suggested that CSF administration may improve overall survival and cure rate in this population by both decreasing treatmentrelated morbidity and, maintaining dose intensity, in accordance with the Goldie and Coldman (1983) hypothesis.

Although a recent meta-analysis of the above studies and those conducted in Hodgkin's lymphoma (Bohlius et al, 2004) has confirmed a $26 \%(95 \%$ CI $11-38 \%)$ reduction in the risk of febrile neutropenia with CSF prophylaxis, no overall survival benefit was noted despite a modest increase in the median cytotoxic dose intensities achieved in the arms receiving CSFs being reported in most studies.

*Correspondence: Dr AR Clamp; E-mail: Andrew.clamp@christie.nhs.uk Revised 19 May 2008; accepted 28 May 2008; published online I July 2008
However, the median follow-up of surviving patients in the trials included in the meta-analysis was relatively short at 4.4 years (range, 1.3-7.9 years) and all cause mortality was analysed. We therefore decided to analyse long-term follow-up data from the first published randomised study of G-CSF administration in NHL patients (Pettengell et al, 1992) to determine whether the use of G-CSF and consequent increase in chemotherapy dose intensity will impact long-term survival, overall morbidity or the development of unexpected late complications.

\section{PATIENTS AND METHODS}

\section{Patients}

Eighty patients aged 16-71 years with high-grade NHL (Kiel) of any disease stage/performance status commencing VAPEC-B chemotherapy were entered between August 1989 and March 1991. Fortyone were randomised to receive G-CSF (filgrastim (Amgen, Thousand Oaks, CA, USA) $-230 \mathrm{mcg} \mathrm{m}^{-2}$ by daily subcutaneous injection for 13 weeks apart from days preceding and during myelosuppressive chemotherapy administration) in addition to chemotherapy and 39 received chemotherapy alone. Pretreatment characteristics of the two groups were well matched for prognostic factors (see Table 1). Thirty-four patients (83\%) receiving G-CSF and $29(74 \%)$ in the control group completed chemotherapy. 
Table I Patient characteristics at trial entry and dose intensity of treatment received

\begin{tabular}{|c|c|c|}
\hline & G-CSF $(n=4 I)$ & Control $(n=39)$ \\
\hline \multicolumn{3}{|l|}{ Age (years) } \\
\hline Median (range) & $51(16-67)$ & $53(22-7 \mid)$ \\
\hline \multicolumn{3}{|l|}{ Gender } \\
\hline Male & 27 & 26 \\
\hline Female & 14 & 13 \\
\hline \multicolumn{3}{|l|}{ ECOG PS } \\
\hline 0 & 6 & 4 \\
\hline I & 21 & 19 \\
\hline 2 & 11 & 13 \\
\hline 3 & 3 & 3 \\
\hline \multicolumn{3}{|l|}{ Disease stage } \\
\hline I & 9 & 8 \\
\hline$\|$ & 12 & 14 \\
\hline III & 5 & 3 \\
\hline IV & 15 & 14 \\
\hline B symptoms & 15 & 17 \\
\hline \multicolumn{3}{|c|}{ Histology (working formulation) } \\
\hline High & 35 & 33 \\
\hline Intermediate & 5 & 5 \\
\hline Unclassified & । & । \\
\hline \multicolumn{3}{|l|}{ IPI risk grouping } \\
\hline Low & 25 & 26 \\
\hline Low-intermediate & 5 & 6 \\
\hline High-intermediate & 6 & 2 \\
\hline High & 5 & 5 \\
\hline \multicolumn{3}{|l|}{ Median dose intensity } \\
\hline Whole regimen & $95 \%$ & $83 \%$ \\
\hline Adriamycin & $96 \%$ & $85 \%$ \\
\hline Cyclophosphamide & $96 \%$ & $83 \%$ \\
\hline Etoposide & $94 \%$ & $82 \%$ \\
\hline
\end{tabular}

ECOG PS = Eastern Cooperative Oncology Group performance status.

Patients randomised to receive G-CSF achieved $12 \%$ greater median dose intensity than control patients (95 vs 83\%) - see Table 1 for median dose intensities of adriamycin, cyclophosphamide and etoposide.

Following completion of treatment, clinical details and disease status were regularly updated in the trial database either from out patient clinic annotations or by liaison with the patient's primary care physicians. Causes of death were retrieved from case notes or death certification. The case notes of all patients who had died since the previous publication or who had been designated as a non-lymphoma death in the trial database were reviewed by two authors (AC, JR).

\section{Statistical methods}

The objectives of the study were to evaluate the long-term effects of the use of G-CSF and increased dose-intensity chemotherapy on overall survival and mortality patterns. Definitions of reported end points are as follows (Cheson et al, 2007).

Overall survival (OS) - time from randomisation to death from any cause.

Freedom from progression (FFP) - time from randomisation to first documentation of disease progression.

Progression-free survival (PFS) - time from randomisation to the first of disease progression or death from any cause.

All analyses were performed on an intention-to-treat basis. Kaplan and Meier, (1958) survival curves were drawn for overall survival and progression-free survival and compared between the treatment groups using the log-rank test. The proportions of patients having experienced an event at 10 years were estimated from the survival curves.

To assess the effects of specific causes of death, cumulative incidence curves were constructed in a competing risks framework. The cumulative incidence of death from cause $\mathrm{x}$ at time $\mathrm{t}$ is the probability of dying from $\mathrm{x}$ by time $\mathrm{t}$ in an environment where other causes of death are acting. The treatment groups were then compared using Gray's test (Gray, 1988).

A further analysis was also performed by fitting a multi-state Cox illness/death model (Andersen et al, 1993) for the three outcomes initial progression, death without progression and death following progression. This formulation of the Cox regression model allowed us to control for the potential effects of age, sex and international prognostic index score (International Non-Hodgkin's lymphoma prognostic factors project, 1993).

Relative mortality models (Andersen et al, 1993) were estimated for each trial arm separately using England and Wales death rates broken down by sex, age (integer years) and period (annually up until 2005, 2005 figures used for follow-up in 2006) obtained from the Human Mortality database (2008).

\section{RESULTS}

Forty-eight of the eighty initial patients had died at the time of this analysis. The median follow up of the 36 surviving patients was 15.7 years (range, 8.4-16.9 years). Of the 48 dead, 24 died in the G-CSF arm and 24 in the control arm. Ten-year overall survival figures were 51 and $46 \%$ in the G-CSF and control arms respectively and 10-year PFS 49 and $44 \%$.

The Kaplan-Meier survival curves for OS and FFP are illustrated in Figure $1 \mathrm{~A}$ and $1 \mathrm{~B}$ respectively. Although $\mathrm{OS}$ and PFS (data not shown) were virtually identical in both arms, FFP was significantly higher in the interventional arm receiving G-CSF and consequently $12 \%$ higher dose intensity of chemotherapy (10-year FFP 68 and 47\% for G-CSF and control arms respectively) suggesting an imbalance in the causes of death between the two arms. It was therefore decided to examine this in more detail and these results are summarised in Table 2.

Eleven of 41 patients in the G-CSF arm had documented progressive disease and 10 of these have subsequently died from NHL. In the control arm, 21 of the 39 patients had disease progression with 19 dying because of this $(P=0.02)$. The cumulative incidence curves for lymphoma-specific death are shown in Figure 1C. Paradoxically, 14 patients in the G-CSF arm died from causes other than progressive NHL compared with five in the control arm $(P=0.02)$ (Figure 1D).

To assess whether known lymphoma-related prognostic factors may have influenced these findings, we controlled these using a multi-state formulation of Cox regression model analysis (Table 3 ). Age, sex, international prognostic index score and treatment arm were analysed as separate variables. Unfortunately, baseline data on known cardiovascular and second cancer risk factors for example, smoking history, hypertension, serum cholesterol were not routinely collected and so could not be included in this analysis. However, the random allocation of patients to the two treatment arms should allow for the equal distribution of these risk factors between the two arms. This analysis confirmed that patients receiving G-CSF were less likely to experience lymphoma progression (HR $0.40 ; 95 \%$ CI $0.18-0.87$ ) than controls but were more likely to die prior to lymphoma progression (HR 3.08; $95 \%$ CI 1.05-8.99).

Of the 14 non-NHL deaths in the G-CSF arm, three patients died from treatment-related infections, two from neutropenic infections during the 11-week treatment schedule and one from autopsyconfirmed invasive aspergillosis 3 months after commencement of 

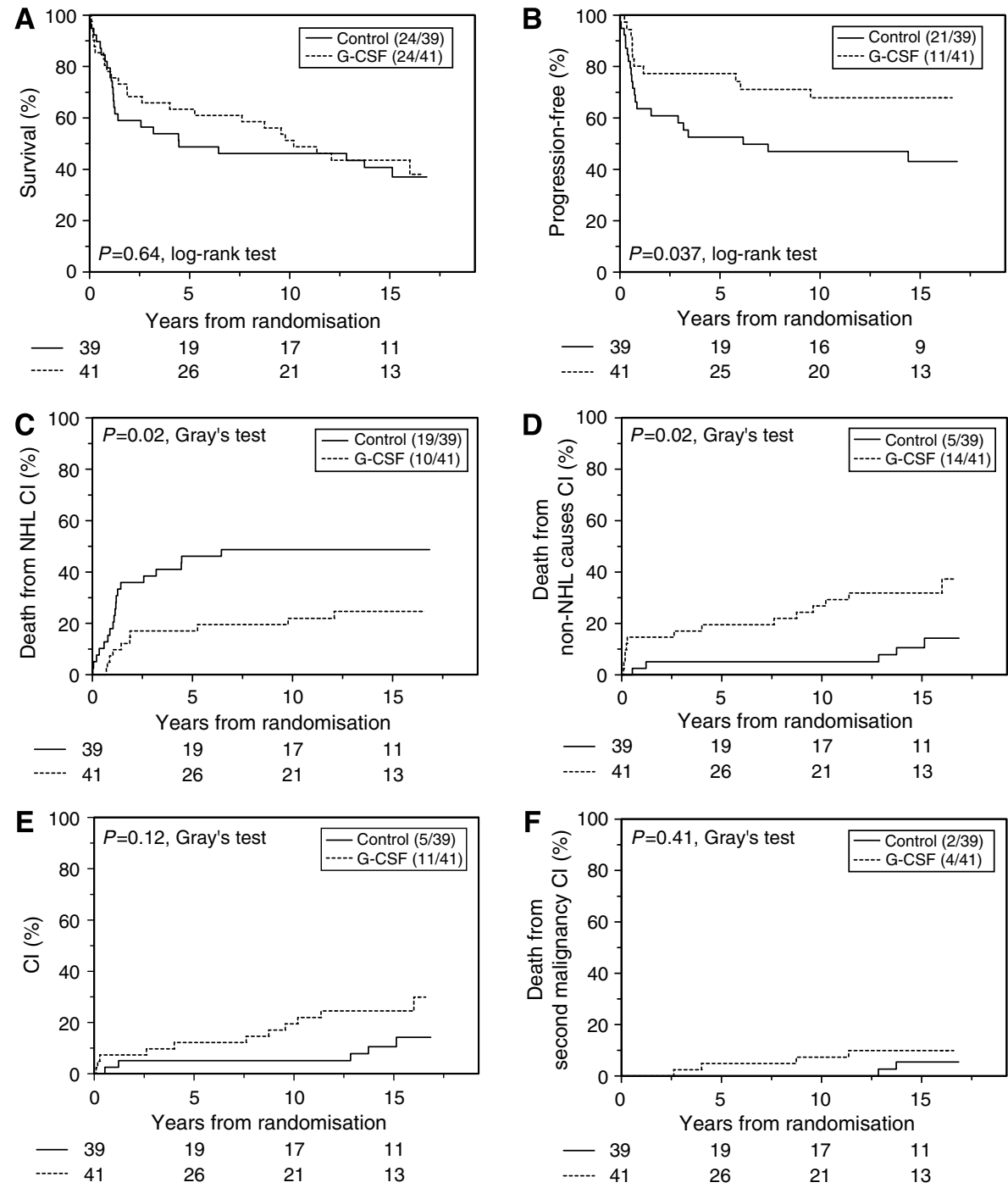

Figure I Survival end points. Survival curves comparing chemotherapy-alone arm (solid line) and chemotherapy + G-CSF arm (dashed line). KaplanMeier plots for $(\mathbf{A})$ overall survival $(\mathbf{B})$ freedom from progression. Cumulative incidence curves for $(\mathbf{C}) \mathrm{NHL}$-specific death $(\mathbf{D})$ non-NHL deaths $(\mathbf{E})$ death from causes other than progressive NHL and acute treatment-related infections (F) Deaths from second malignancy.

Table 2 Patient status at last follow-up

\begin{tabular}{lcccccccc}
\hline & $\begin{array}{c}\text { Patients } \\
\text { treated }\end{array}$ & $\begin{array}{c}\text { Alive and } \\
\text { well (\%) }\end{array}$ & $\begin{array}{c}\text { Alive with } \\
\text { progressive } \\
\text { disease (\%) }\end{array}$ & $\begin{array}{c}\text { Dead from } \\
\text { NHL (\%) }\end{array}$ & $\begin{array}{c}\text { Dead from } \\
\text { treatment-related } \\
\text { infection (\%) }\end{array}$ & $\begin{array}{c}\text { Dead from } \\
\text { second } \\
\text { malignancy (\%) }\end{array}$ & $\begin{array}{c}\text { Dead from } \\
\text { other causes } \\
\text { (\%) }\end{array}$ & $\begin{array}{c}\text { Cause of death } \\
\text { not identified } \\
\text { (\%) }\end{array}$ \\
\hline G-CSF & 41 & $17(41)$ & 0 & $10(24)$ & $3(7)$ & $4(10)$ & $6(15)$ & $1(2)$ \\
Control & 39 & $13(33)$ & $2(5)$ & $19(46)$ & 0 & $2(5)$ & $2(5)$ & $1(3)$ \\
\hline
\end{tabular}

Median follow-up for surviving patients is 15.7 years (range, 8.4-16.9).

Table 3 Hazard ratio estimates (95\% confidence interval) for three transitions in a multi-state cox illness/death model

\begin{tabular}{llcr}
\hline & Progression $(\boldsymbol{n}=\mathbf{3 2 / 8 0})$ & Death without progression $(\boldsymbol{n}=\mathbf{1 8 / 8 0})$ & Death following progression $(\boldsymbol{n}=\mathbf{3 0 / 3 2})$ \\
\hline Male vs female & $1.07(0.50,2.29) P=0.86$ & $1.14(0.41,3.16) P=0.80$ & $0.99(0.36,2.7 I) P=0.98$ \\
Age (years) & $0.99(0.96,1.02) P=0.51$ & $\mathbf{I . 1 3}(\mathbf{I . 0 5}, \mathbf{I . 2 1}) \mathbf{P}=\mathbf{0 . 0 0 2}$ & $1.02(0.98,1.06) P=0.34$ \\
IPI (integer score) & $\mathbf{I . 5 7}(\mathbf{I . 2 3}, \mathbf{2 . 0 1}) \mathbf{P}=\mathbf{0 . 0 0 0 3}$ & $1.19(0.84,1.69) P=0.34$ & $1.38(0.98,1.94) P=0.06$ \\
G-CSF vs control & $\mathbf{0 . 4 0}(\mathbf{0 . 1 8} \mathbf{0 . 8 7}) \mathbf{P}=\mathbf{0 . 0 2}$ & $\mathbf{3 . 0 8}(\mathbf{I . 0 5}, \mathbf{8 . 9 9}) \mathbf{P}=\mathbf{0 . 0 4}$ & $0.69(0.25,1.85) P=0.46$ \\
\hline
\end{tabular}

$\mid \mathrm{PI}=$ international prognostic index. Significant hazard ratios are shown in bold. 
chemotherapy. No patient in the control arm died from treatmentrelated infection.

Eleven deaths in the G-CSF arm and five in the control arms were not due to NHL or treatment-related infection $(P=0.12)$ (cumulative incidence curves Figure 1E). It was impossible to assign a cause in two patients (one in each arm). Four patients who received G-CSF died from second malignancies compared to two in the control arm (Figure 1F). In total, second cancers were documented in seven patients, five in the G-CSF arm and two in the control arm. There were two cases of lung cancer (diagnosed 42 and 105 months after commencement of chemotherapy) and one each of acute myeloid leukaemia (28 months), breast cancer (76 months) and disseminated cancer (131 months- no histological diagnosis possible) in the G-CSF arm. In the control arm, two cases of lung cancer (54 and 159 months) were diagnosed. One case of localised cutaneous squamous cell carcinoma was also documented in the control arm.

Table 4 Causes of non-lymphoma deaths

\begin{tabular}{|c|c|c|c|}
\hline \multicolumn{2}{|l|}{ G-CSF } & \multicolumn{2}{|l|}{ Control } \\
\hline Cause & $\begin{array}{l}\text { TTD } \\
\text { (mos) }\end{array}$ & Cause & $\begin{array}{l}\text { TTD } \\
\text { (mos) }\end{array}$ \\
\hline \multicolumn{4}{|l|}{ Second cancer } \\
\hline AML & 28 & NSCLC & 154 \\
\hline NSCLC & 48 & $\mathrm{NSCLC}$ & 165 \\
\hline NSCLC & 104 & & \\
\hline Metastatic carcinoma & 131 & & \\
\hline \multicolumn{4}{|l|}{ Cardiovascular disease } \\
\hline $\mathrm{MI}$ & 2 & & \\
\hline $\mathrm{Ml}$ & 3.5 & & \\
\hline Cardiac failure & 115 & & \\
\hline $\mathrm{Ml}$ & 134 & & \\
\hline $\mathrm{IHD}$ & 192 & & \\
\hline \multicolumn{4}{|l|}{ Other } \\
\hline Intracerebral haemorrhage & 3 & Not known & 6.5 \\
\hline Not known & 92 & PCP & 14 \\
\hline & & $\begin{array}{l}\text { Cirrhosis secondary } \\
\text { to Hepatitis C }\end{array}$ & 182 \\
\hline
\end{tabular}

$\mathrm{AML}=$ acute myeloid leukaemia; $\| \mathrm{HD}=$ ischaemic heart disease; $\mathrm{Ml}=$ myocardial infarction; NSCLC $=$ Non-small cell lung cancer; $P C P=$ pneumocystis carinii pneumonia. Deaths from treatment-related infections are not included.

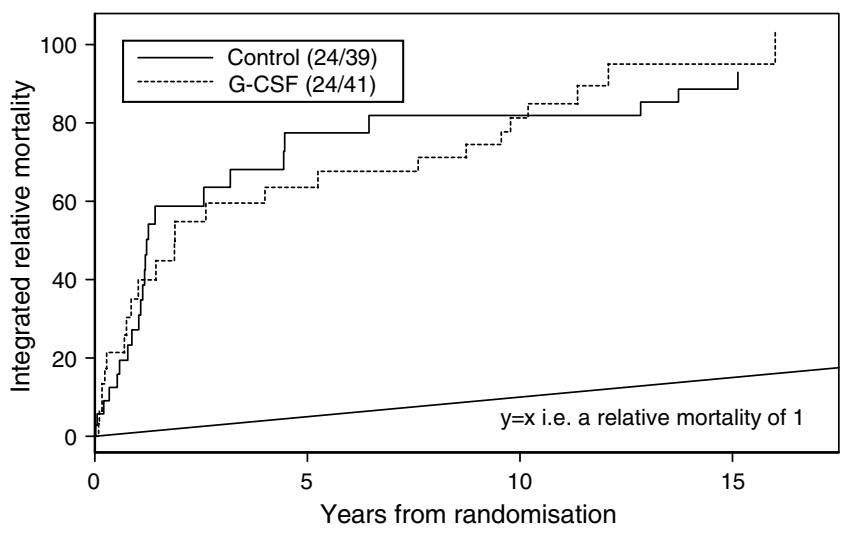

Figure 2 Relative mortality models. Relative mortality functions were estimated for each trial arm separately. While relative mortality rates in the chemotherapy alone arm return close to the underlying population with continued follow-up (slope gradient close to I), rates appear to remain somewhat higher in the G-CSF treated arm.
Of the six other deaths in the G-CSF arm, five died from cardiovascular disease (three myocardial infarctions, one congestive cardiac failure and one ischaemic heart disease) and one from an intracerebral haemorrhage. In the control arm, one patient died from Pneumocystis carinii pneumonia 14 months after chemotherapy with no evidence of recurrent NHL and one from cirrhosis secondary to chronic hepatitis $\mathrm{C}$ infection. The causes of non-lymphoma deaths are summarised in Table 4.

One possible explanation for these findings is that because patients who were exposed to G-CSF appeared less likely to experience progression of lymphoma, they were exposed to other competing causes of death for longer than patients who did not receive G-CSF but with the proportional rate of non-lymphomarelated mortality being the same in both groups. To assess this possibility, we constructed relative mortality models for each trial arm separately using England and Wales death rates broken down by sex, age (integer years) and period (annually up until 2005, 2005 figures used for follow-up in 2006) obtained from the Human Mortality Database (Figure 2). This analysis tentatively indicates that after the period of early excess relative mortality associated primarily with lymphoma-related events, the relative mortality rate in the surviving subjects appears somewhat higher in the G-CSF treated subjects than in those who received chemotherapy alone.

\section{DISCUSSION}

There have been numerous randomised studies on the use of G-CSF during induction chemotherapy for high-grade NHLs (Pettengell et al, 1992; Bastion et al, 1993; Gerhartz et al, 1993; Aviles et al, 1994; Engelhard et al, 1994; Gisselbrecht et al, 1997; Zinzani et al, 1997; Doorduijn et al, 2003; Osby et al, 2003). While a recent meta-analysis (Bohlius et al, 2004) of these indicates a clinical benefit in terms of reducing the risk of febrile neutropenia, no clear improvement was demonstrable in terms of tumour response or survival parameters. However, follow-up was short (median 4.4 years) and cause-specific survival was not analysed.

In this report, we detail long-term pharmacovigilance follow up of the first randomised study of G-CSF during induction chemotherapy for high-grade NHL (Pettengell et al, 1992). No such extended follow-up has previously been presented. While progression-free and overall survival figures were similar in the cohort of patients receiving G-CSF and those in the control arm (Table 1), a difference was noted in the percentage of patients free from lymphoma progression at 10 years $(68 \%$ G-CSF intervention arm vs $47 \%$ control arm). This prompted us to further investigate the mortality patterns of the two study groups, which were wellbalanced at original randomisation for age, sex and performance status (Table 1). Nineteen patients in the control group died from progressive NHL compared with 10 in the G-CSF group $(P=0.02)$ while five died from other causes in the control group compared with 14 in the G-CSF group $(P=0.02)$. Despite the small size and retrospective nature of our analysis, this observation could support the hypothesis that the use of G-CSF to facilitate chemotherapy administration allows greater lymphoma-specific survival at the expense of death from other causes. However, our analysis is limited by the lack of baseline information on major risk factors for both second malignancies and cardiovascular disease including smoking and family histories, hypertension, diabetes and cholesterol levels. The random allocation of patients to treatment arm will have limited uneven distribution of these variables between the two treatment arms but we cannot exclude biased distribution as an explanation of our findings.

An excess of deaths from acute treatment-related infective complications were noted in the intervention arm of our study. The reasons for this are unclear. Identical cytotoxic dose modification criteria were applied in both groups and G-CSF administration reduced the risk of febrile neutropenia. No 
increased on-chemotherapy mortality was seen associated with G-CSF administration in the Bohlius meta-analysis (relative risk- $0.9395 \%$ CI $0.60-1.43$ ) (Bohlius et al, 2004).

Eleven patients died from other causes in the G-CSF arm compared with five in the control arm $(P=0.12)$. The occurrence of deaths from second malignancy and cardiovascular disease which account for the majority of these (9; G-CSF vs 2; control) are of particular interest as it is now apparent from large epidemiologic analyses of NHL databases that long-term NHL survivors are at increased risk from these treatment-related complications.

\section{Second malignancy}

An increased incidence of second malignancy has been reported in most but not all retrospective cohort studies (Travis et al, 1993; André et al, 2004; Moser et al, 2006a; Mudie et al, 2006). Although André et al (2004) failed to demonstrate an overall increased risk of second cancer after a median follow-up of 74 months in 2837 patients with NHL treated with adriamycin-cyclophosphamidevindesine-bleomycin-prednisolone, they noted an excess of myeloid malignancies and an increased risk of lung cancer in males. Other studies have demonstrated a 20-30\% overall increased incidence of malignancy primarily due to increased rates of leukaemia, lung and possibly colorectal cancers (Travis et al, 1993; Moser et al, 2006a; Mudie et al, 2006). It is also apparent that this elevated risk persists for at least 15 years after NHL treatment and is inversely related to age at diagnosis.

There are several studies that suggest that the use of G-CSF may increase the risk of secondary myeloid malignancies during followup (Relling et al, 2003; Hershman et al, 2007) however, evidence from NHL studies are lacking. G-CSF to facilitate dose dense chemotherapy (two vs three weekly CHOP) in the first-line therapy of aggressive NHL (Pfreundschuh et al, 2004a, b) improved 5-year event-free and overall survivals without any significant increase in the incidence of second cancers in the dose dense treatment arms after 58 months median follow-up. The total dose of chemotherapy delivered was identical in both arms and it is possible that followup in these studies is not yet long enough to detect any differences.

Although increased dose intensity may be postulated as one contributory factor to an increase in the incidence of second malignancies in patients exposed to G-CSF in this study, experimental studies have implicated a mechanistic role for CSFs in the potentiation of neoplastic progression. CSFs have been implicated as direct promoters of both tumour cell growth and migration (Mueller et al, 1999; Obermuller et al, 2004) and have also been shown to have paracrine as well as autocrine tumour promoting properties as they modulate the tumour stroma and enhance angiogenesis in a squamous skin carcinoma model (Obermuller et al, 2004).

\section{Cardiovascular disease}

Although the long-term risk of cardiovascular disease in patients treated for aggressive NHL has not been extensively investigated, an increased incidence of chronic heart failure (SIR 5.4, 95\% CIs 4.1-6.9) has been reported in one retrospective cohort study of 592 patients (Moser et al, 2006b). Although no overall increase in myocardial infarction was noted, the risk was elevated in patients with at least 5 years follow-up. This is consistent with data from the Collaborative British Cohort Study in Hodgkin's disease (Swerdlow et al, 2007), which noted increased risks of myocardial infarction associated with anthracycline and vincristine-containing chemotherapy regimens that were significant even in the absence of supradiaphragmatic radiotherapy.

How G-CSF could affect the long-term incidence of cardiovascular disease is less clear. Although patients receiving G-CSF achieved a $12 \%$ increased adriamycin dose intensity, total dose $\left(200 \mathrm{mg} \mathrm{m}^{-2}\right)$ was still well below the conventional ceiling dose for clinically apparent cardiotoxicity of $400-450 \mathrm{mg} \mathrm{m}^{-2}$. It is also intriguing to note that G-CSF appears to protect from anthracycline cardiomyopathy in animal models (Hou et al, 2006) and has been proposed as a possible preventive agent in the clinic (Takemura and Fujiwara, 2007).

To conclude, this unique long-term follow-up data of the first randomised study investigating the use of G-CSF in the first-line chemotherapeutic treatment of high-grade NHL suggests that although overall survival is not altered by this intervention, the pattern of mortality may be changed. Although potential long-term increased risk of second malignancy and cardiovascular disease in patients receiving G-CSF is intriguing and may have significant implications, the small size of the original study cohorts, lack of information on other known risk factors and the post hoc nature of this analysis limits the conclusions that can be drawn. However, this analysis emphasises the need for long-term and detailed follow-up of patients enrolled into such studies and the sharing of these data for the purposes of meta-analysis.

\section{REFERENCES}

Andersen PK, Borgan O, Gill RD, Keiding N (1993) Statistical Models Based On Counting Processes. Springer: Verlag, New York

André M, Mounier N, Leleu X, Sonet A, Brice P, Henry-Amar M, Tilly H, Coiffier B, Bosly A, Morel P, Haioun C, Gaulard P, Reyes F, Gisselbrecht C (2004) Second cancers and late toxicities after treatment of aggressive non-Hodgkin's lymphoma with the ACBVP regimen: a GELA cohort of 2837 patients. Blood 103: $1222-1228$

Aviles A, Diaz-Maqueo J, Talavera A, Nambo M, Garcia E (1994) Effect of granulocyte colony-stimulating factor in patients with diffuse large cell lymphoma treated with intensive chemotherapy. Leuk Lymphoma 15: $153-157$

Bastion Y, Bosly A, Gisselbrecht C, Reyes F, Tilly H, Herbrecht R (1993) A randomized double-blind phase III study of filgrastim (recombinant human G-CSF) vs placebo during intensive induction chemotherapy in 55 to 59 year old patients with poor prognosis aggressive non-Hodgkin's lymphoma. Blood 82(Suppl 1): 143a

Bohlius J, Reiser M, Schwarzer G, Engert A (2004) Granulopoeisis stimulating factors to prevent adverse effects in the treatment of malignant lymphoma (review). The Cochrane database of systematic reviews, Issue 3 Art No.CD003189.pub03

Cheson BD, Pfistner B, Juweid ME, GAscoyne RD, Specht L, Horning SJ, Coiffier B, Fisher PL, Hagenbeek A, Zucca E, Rosen ST, Stroobants S,
Lister TA, Hopper RT, Dreyling M, Tobinai K, Vose JM, Connor JM, Federico M, Diehl V (2007) Revised response criteria for malignant lymphoma. J Clin Oncol 25: 579-596

Doorduijn J, van der Holt B, van Imhoff G, van der Hem K, Kramer M, van Oers M, Ossenkoppele G, Schaafsma M, Verdonck L, Verhoef G, Steijaert M, Buijt I, Uyl-de Groot C, van Agthoven M, Mulder A, Sonneveld P (2003) CHOP compared with CHOP plus granulocyte colony-stimulating factor in elderly patients with aggressive non-Hodgkin's lymphoma. J Clin Oncol 21: 3041 - 3050

Engelhard M, Gerhatz H, Brittinger G, Engert A, Fuchs R, Geisler B, Gerhatz D, Haunauske A, Hartlapp H, Huhn D (1994) Cytokine efficiency in the treatment of high grade malignant non-Hodgkin's lymphomas: results of a randomized double-blind placebo-controlled study with intensified COP-BLAM +/- rhGM-CSF. Ann Oncol 5(Suppl 2): 123-125

Gerhartz H, Engelhard M, Meusers P, Brittinger G, Wilmanns W, Schlimok G, Mueller P, Huhn D, Musch R, Siegert W, Gerhartz D, Hartlapp J, Thiel E, Huber C, Peschl C, Spann W, Emmerich B, Schadek C, Westerhausen M, Pees H-W, Radtke H, Engert A, Terhadt E, Schick H, Binder T, Fuchs R, Hasford J, Brandmaier R, Stern A, Jones T, Ehrlich H, Stein H, Parwaresch M, Tiemann M, Lennert K (1993) Randomized double-blind placebo-controlled, Phase III study of recombinant human granulocytemacrophage colony-stimulating factor as adjunct to induction treatment 
of high-grade malignant Non-Hodgkin's lymphomas. Blood 82 $2329-2339$

Gisselbrecht C, Haioun C, Lepage E, Bastion Y, Tilly H, Bosly A, Dupriez B, Marit G, Herbrecht R, Deconinck E, Marolleau J, Yver A, DabouzHarrouche F, Coiffier B, Reyes F (1997) Placebo-controlled phase III study of lenogastrim (glycosylated recombinant human granulocyte colonystimulating factor) in aggressive non-Hodgkin's lymphoma: factors influencing chemotherapy administration. Leuk Lymphoma 25: 289-300

Goldie J, Coldman A (1983) Quantitative model for multiple levels of drug resistance in clinical tumours. Cancer Treat Rep 67: 923-931

Gray RJ (1988) A class of k-sample tests for comparing the cumulative incidence of a competing risk. Ann Stat 16: $1141-1154$

Hershman D, Neugut AI, Jacobson JS, Wang J, Tsai W-Y, McBride R, Bennett CL, Grann VR (2007) Acute myeloid leukaemia and myelodysplastic syndrome following use of granulocyte colony-stimulating factors during breast cancer adjuvant chemotherapy. J Natl Cancer Inst 99: $1962-1965$

Hou XW, Son J, Wang Y, Ru YX, Lian Q, Majiti W, Amazouri A, Zhou YL, Wang PX, Han ZC (2006) Granulocyte colony-stimulating factor reduces cardiomyocyte apoptosis and improves cardiac function in adriamycininduced cardiomyopathy in rats. Cardiovasc Drug Ther 20: 85-91

Human Mortality Database. University of California, Berkeley (USA), and Max Planck Institute for Demographic Research (Germany) (2008) Available at www.mortality.org or www.humanmortality.de (data downloaded on $17 / 04 / 2008$ )

Kaplan EL, Meier P (1958) Non-parametric estimation from incomplete observations. J Am Stat Assoc 53: 457

Moser EC, Noordijk EM, van Leeuwen FE, Baars JW, Thomas J, Carde P, Meerwaldt JH, van Glabbeke M, Kluin-Nelemans HC (2006a) Risk of second cancer after treatment of aggressive non-Hodgkin's lymphoma; an EORTC cohort study. Haematologica 91: 1481-1488

Moser EC, Noordijk EM, van Leeuwen FE, Cessie S, Baars JW, Thomas J, Carde P, Meerwaldt JH, van Glabbeke M, Kluin-Nelemans HC (2006b) Long-term risk of cardiovascular disease after treatment for aggressive non-Hodgkin's lymphoma. Blood 107: 2912-2919

Mudie NY, Swerdlow AJ, Higgins CD, Smith P, Qiao Z, Hancock BW, Hoskin PJ, Linch DC (2006) Risk of second malignancy after NonHodgkin's lymphoma: A British cohort study. J Clin Oncol 24: 1568 - 1574

Mueller M, Merold-Munde C, Riede D, Lange M, Steiner H, Fusenig N (1999) Autocrine growth regulation by granulocyte colony-stimulating factor and granulocyte macrophage colony-stimulating factor in human gliomas with tumour progression. Am J Pathol 155: 1557-1567

Obermuller E, Vosseler S, Fusenig N, Mueller M (2004) Cooperative autocrine and paracrine functions of granulocyte colony-stimulating factor and granulocyte-macrophage colony-stimulating factor in the progression of skin carcinoma cells. Cancer Res 64: 7801 - 7812
Osby E, Hagberg H, Kvaloy S, Teerenhovi L, Anderson H, Cavallin-Stahl E, Holte H, Myhre J, Pertovaara H, Bjorkholm M (2003) CHOP is superior to CNOP in elderly patients with aggressive lymphoma while outcome is unaffected by filgrastim treatment: results of a Nordic Lymphoma Group randomized trial. Blood 101: 3840-3848

Pettengell R, Gurney H, Radford J, Deakin D, James R, Wilkinson P, Kane K, Bentley J, Crowther D (1992) Granulocyte colony-stimulating factor to prevent dose-limiting Neutropenia in Non-Hodgkin's Lymphoma: a randomised controlled trial. Blood 80: 1430-1436

Pfreundschuh M, Trumper L, Kloess M, Schmits R, Feller AC, Rube C, Rudolph C, Reiser M, Hossfeld DK, Eimermacher H, Hasenclever D, Schmitz N, Loeffler M (2004a) Two-weekly or 3-weekly CHOP chemotherapy with or without etoposide for the treatment of elderly patients with aggressive lymphomas: results of the NHL-B2 trial of the DSHNHL. Blood 104: 634-641

Pfreundschuh M, Trumper L, Kloess M, Schmits R, Feller AC, Rudolph C, Reiser M, Hossfeld DK, Metzner B, Hasenclever D, Schmitz N, Glass B, Rube C, Loeffler M (2004b) Two-weekly or 3-weekly CHOP chemotherapy with or without etoposide for the treatment of young patients with good prognosis (normal LDH) aggressive lymphomas: results of the NHL-B2 trial of the DSHNHL. Blood 104: 626-633

Relling MV, Boyett JM, Blanco JG, Raimondi S, Behm FG, Sandlund JT, Rivera GK, Kun LE, Evans WE, Pui CH (2003) Granulocyte colonystimulating factor and the risk of secondary myeloid malignancy after etoposide treatment. Blood 15: $3862-3867$

Swerdlow AJ, Higgins CD, Smith P, Cunningham D, Hancock BW, Horwich A, Hoskin PJ, Lister A, Radford JA, Rohatiner AZS, Linch DC (2007) Myocardial infarction mortality risk after treatment for Hodgkin's disease: a collaborative British cohort study. J Natl Cancer Inst 99: $206-214$

Takemura G, Fujiwara H (2007) Doxorubicin-induced cardiomyopathy from the cardiotoxic mechanisms to management. Prog Cardiovasc Dis 49: $330-351$

The International Non-Hodgkin's Lymphoma Prognostic Factors Project (1993) A predictive model for aggressive Non-Hodgkin's lymphoma. New Engl J Med. 329: 987-994

Travis LB, Curtis RE, Glimelius B, Holowaty E, Van Leeuwen FE, Lynch CF, Adami J, Gospodarowicz M, Wacholder S, Inskip P, Tucker MA, Fraumeni Jr JF, Boice Jr JD (1993) Second cancers in long-term survivors of Non-Hodgkin's lymphoma. J Natl Cancer Inst 85: 1932-1937

Zinzani P, Pavone E, Storti S, Moretti L, FAttori P, Guardigni L, FAlini B, Gobbi M, Gentilini P, Lauta V, Bendandi M, Gherlinzoni F, Magagnoli M, Venturi S, Aitini E, Tabanelli M, Leone G, Liso V, Tura S (1997) Randomized trial with or without granulocyte colony-stimulating factor as adjunct to induction VNCOP-B treatment of elderly high grade Non-Hodgkin's lymphoma. Blood 89: 3947-3979 